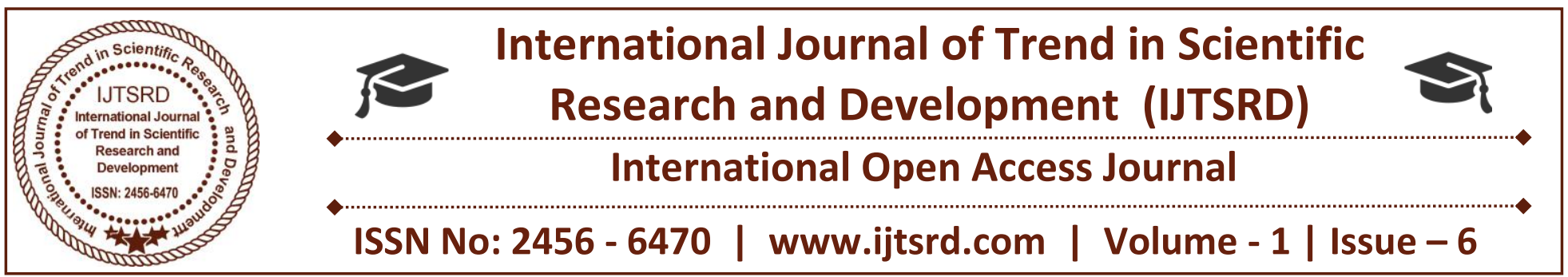

\title{
Prototype of Total Artificial Heart System
}

\author{
Mr. A. Ravi Shankar \\ Assistant Professor, Dept. of Electronics and \\ Communication Engineering, Sri Vasavi Institute of \\ Engineering and Technology, Nandamuru, Pedana
}

\author{
Dr. S. Kishore Reddy \\ Assistant Professor, Dept. of Electrical and Computer \\ Engineering, College of Electrical and Mechanical \\ Engineering, Addis Ababa Science \& Technology \\ University
}

\begin{abstract}
Dr. Sultan Feisso
Dean \& Assistant Professor, Dept. of Electrical and Computer Engineering, College of Electrical and Mechanical Engineering, Addis Ababa Science \& Technology University
\end{abstract}

\section{ABSTRACT}

Everyone knows heart is a vital organ. Your heart is the engine inside your body that keeps everything running. Basically, the heart is a muscular pump that maintains oxygen and blood circulation through your lungs and body. Like any engine, if the heart is not well taken care of it can break down and pump less efficiently, a condition called heart failure. There are many people suffering with heart problems and heart failure problems. Until recently, the only option for many severe heart failure patients has been heart transplants and VAD (Ventricular Assist Device). Heart Patients hoping to have a heart transplant may not be able to realize their hope because the amount of donor hearts in relation to the amount of patients in need of a donor heart is minuscule. Heart patients looking to have a VAD implant may find that the system is not yet so safe or dependable because the materials used for it have, in the past, run the risk of causing a stroke. Due to the lack of reliable options heart patients have, researchers have been trying to come up with a new method to aid these patients. The most recent success has been the AbioCor Total Artificial Heart System.

In this paper we presented an artificial heart system called The ABIOCOR which overcomes the defects in the above two mentioned methods. We also presented its design and the components present in it and the importance of each component and their function. The
AbioCor System consists of a set of internal components and external components. All of these components keep the artificial heart pumping blood and keep sending that blood throughout the patient's body. The AbioCor System acts as a natural heart and allows the patient to be free of too many restrictions; the patient is allowed to be mobile, and is also allowed to return many of the activities he participated in before undergoing heart failure. The AbioCor is also designed to increase the life expectancy of the heart patient by at least two times

\section{Keywords: Ventricular Assist Device, AbioCor}

\section{INTRODUCTION}

The AbioCor Total Artificial Heart System is designed to give patients with heart failure an option other than heart transplant and Ventricular Assist Device (VAD). VAD Systems are intended for patients with a failing left ventricle; the VAD is implanted and replaces the ventricle by acting as a pump. Heart Patients hoping 


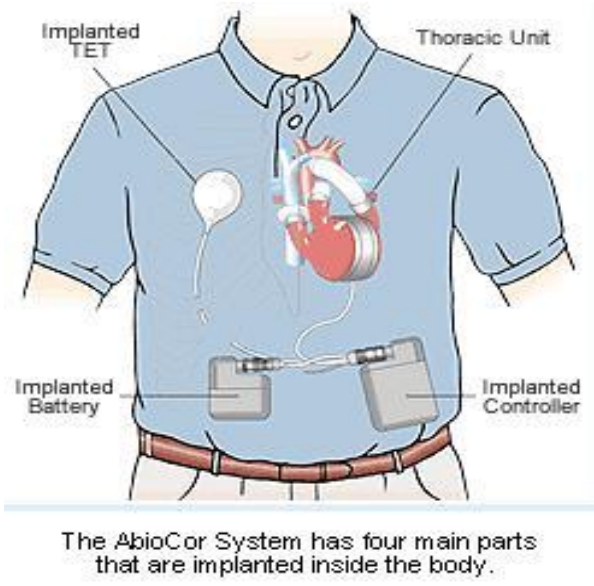

To extend their life expectancy by having a heart transplant may not be able to realize their hope because the amount of donor hearts in relation to the amount of patients in need of a donor heart is minuscule. Heart patients looking to have a VAD implant may find that the system is not yet so safe or dependable because the materials used for it have, in the past, run the risk of causing a stroke. Due to the lack of reliable options heart patients have, researchers have been trying to come up with a new method to aid these patients. The most recent success has been the AbioCor Total Artificial Heart System. The AbioCor System acts as a natural heart and allows the patient to be free of too many restrictions; the patient is allowed to be mobile, and is also allowed to return many of the activities he participated in before undergoing heart failure. The AbioCor is also designed to increase the life expectancy of the heart patient by at least two times (Fact monster).

\section{DESIGN}

The components of the AbioCor system are simple in design; that is, the components are not decorated, nor are they coated with materials that are not necessary. The thoracic unit has a similar physical appearance to the appearance of a natural heart. This is because it contains inflows and outflows; aside from the

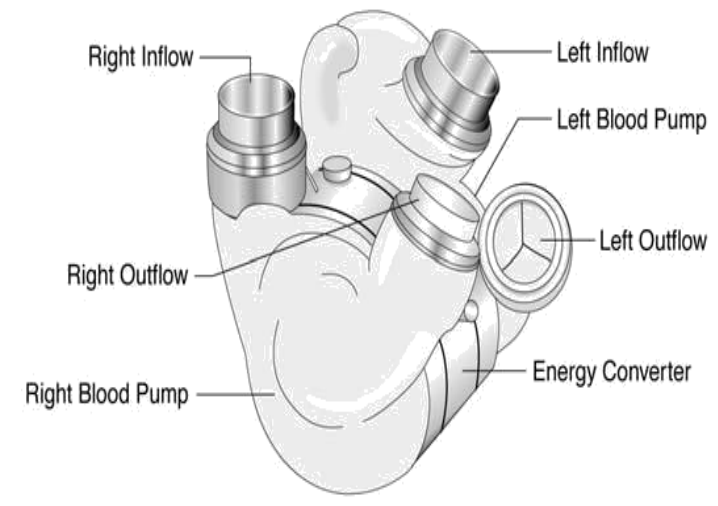

Similarity in inflows and outflows, the thoracic unit is very different from a natural heart because it is made of plastic and titanium and it is not full of veins as a natural heart is. The external and internal TETs are almost identical in their design, they both have a round top and a long thin end (similar to the shape of a lollipop); however, the external TET is covered with silicone. The rest of the AbioCor System's components have geometric designs (mostly rectangular) and are not extravagant in their appearance. For example, the implanted controller and the implanted battery appear very similar; they are both cased in titanium, they both are covered in the solid color of titanium, and they both have the same shape. The console and the PCE control module are generally boxes with no artistic designs or variety in color.

\section{INTERNAL COMPONENTS}

\subsection{Thoracic Unit (Artificial Heart):}

The thoracic unit weighs slightly more than two pounds $(0.9 \mathrm{~kg})$ and is about the same size and shape of a natural heart. It is made of titanium, and Angioflex, a polyurethane plastic. The thoracic unit is implanted in the chest, where a natural heart would be located, and connects to the right and left atria, the aorta, and the pulmonary artery. In order for blood to enter and exit from the unit, grafts must be sewed onto the right and left atria, the aorta, and pulmonary artery of the patient. They must also be sewed onto the thoracic unit's four heart valves. These grafts then allow for the two arteries and the two atria to each be snapped onto the graft of one of the heart valves. Conclusively, one valve will be snapped onto the aorta, another valve will be snapped onto the pulmonary artery, another to the left atrium and another to the right atrium The thoracic unit contains two hydraulic motors; one keeps the blood pumping from each ventricle (blood pump), and the other operates the motion of the four heart valves. The pumping from these hydraulic motors is caused by an oscillating pusher plate that squeezes sacs that then emit blood to the lungs and to the rest of the body (Total Artificial Hearts (TAH)). Additionally, the unit has a left and a right blood pump. Each blood pump has an inflow opening and an outflow opening. When the blood moves to the right blood pump the blood is pumped out through the outflow opening and is led to the lungs. When the blood moves into the left blood opening it will be led to the rest of the body. 


\subsection{Implanted Transmission (TET):}

The implanted TET is an electric coil that provides all of the AbioCor System's internal devices with electrical energy.

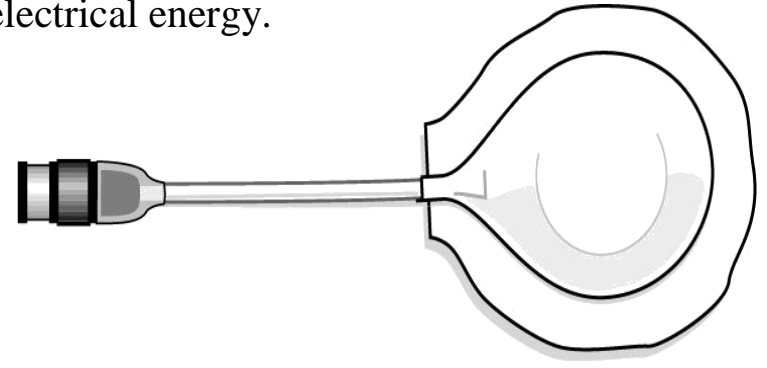

It is connected to the thoracic unit, the implanted controller, and the implanted battery. The implanted TET is located on the upper-left area of the chest (opposite of the artificial heart). In order to fit the patient's insides properly, it has the capability of adjusting its shape. Because the implanted TET provides the AbioCor System with energy without having to run wires in and out of the patient's body, it may also be referred to as a wireless power transfer system. In order to provide internal devices with energy without the use of an external power connection, the implanted TET converts energy from radio waves, sent to it by an external TET, to electrical energy.

\subsection{Implanted Controller:}

The implanted controller is a small automatic computer located in the abdomen of the patient's body. It is secured in a titanium case and connects to all internal components (the implanted TET, the artificial heart, and the implanted battery), meaning that it also receives energy from the implanted TET. The job of the implanted controller is to oversee the internal components of the AbioCor System, to communicate with the AbioCor Console or the Patient-Carried Electronics (PCE), and to control the blood flow output of the artificial heart. In order to monitor all internal components and communicate with external components, the implanted controller exchanges information with the console or the PCE (whether the implanted controller exchanges information with the console or the PCE depends on which of these two power sources the patient is using), if a problem is detected by either of the two external power sources, the patient is immediately notified. The implanted controller is also able to manage the artificial heart's cardiac output rate to make sure that the artificial heat generates the necessary blood flow. The cardiac output rate is the "amount of blood that flows through the heart, expressed in liters per minute. Due to monitoring of blood outflow, the incoming blood flow is guaranteed to match the outgoing blood flow. Aside from working automatically, the implanted controller can also be supervised by a clinician.

\subsection{Implanted Battery}

The implanted battery is placed in the abdomen, opposite from the implanted controller, and is implanted when the implanted controller and the artificial heart are placed in the patient's body. Just like the implanted controller, the implanted battery is kept in a titanium case it receives energy from the external TET, and is connected to all other internal components (in the case of the implanted battery, these internal components are be the artificial heart and the implanted controller)

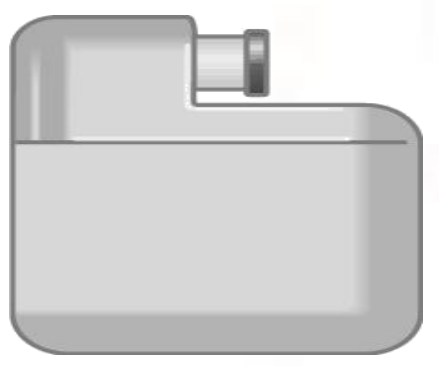

The battery is constantly being recharged by an external battery pack that transfers power to the internal components of the Abercorn System through the external and internal TETs. If the patient were to separate himself from the external TET and battery pack (such as to take a shower), the implanted battery would provide the internal system of the AbioCor with energy for 30 - 40 minutes (Leung, Benedict). The battery itself can last for about a year before it would need to bed replaced. In order to replace it, the patient would be required to receive minor surgery.

\section{EXTERNAL COMPONENTS}

\subsection{External Transcutaneous Energy Transmission (TET):}

The external TET is placed directly over the location of the internal TET to transfer energy through the skin (the external TET is placed over the skin, while the internal TET is placed under the skin, inside the patient's body). 


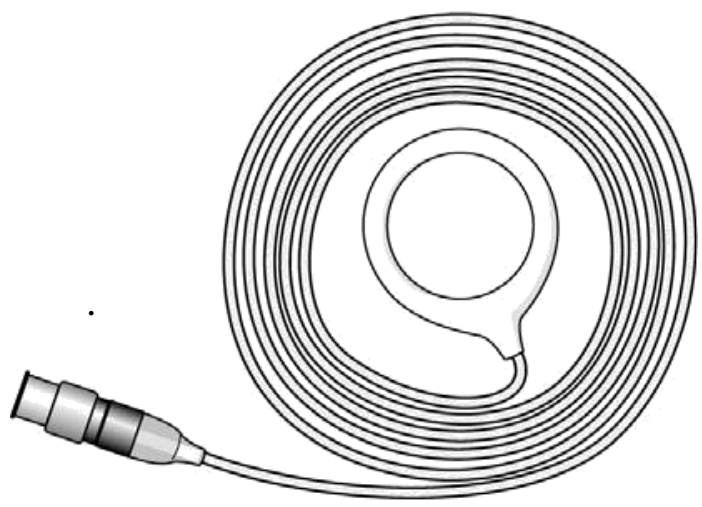

It is connected to the console or the Patient-Carried Electronics (PCE) and is in the form of a silicone ring. The external TET provides the internal TET with energy from either the PCE control module or the AbioCor console. Both of these act as power supplies so what determines which will be used is the location of the patient. If the patient is stationary and is near a power outlet, his source for energy may be the console; if the patient is mobile and has no intentions of remaining in the same location for a long period of time, he may use the PCE as a power source. The several Watts of energy received from the external TET are transmitted to the internal TET in the form of radio waves (Shiba, Kenji). The amount of this energy is enough to penetrate the skin and to be received by the internal TET.

\subsection{Console:}

The console is a small computer containing a keyboard and screen that is used to provide power to the external TET and the internal TET and is also used to communicate with the implanted controller. To provide power to both TETs, the console is plugged into an electrical outlet. The internal TET is then able to transmit energy by being plugged into the back of the console. In order to communicate with the implanted controller, the console uses wireless technology; it consists of an antenna that sends commands to the implanted controller and then receives information regarding the internal components' status. If something goes wrong within the internal system, the console immediately notifies the patient by setting off an alarm sound or alarm lights (Abiomed). In case of a power outage, the console also consists of a backup battery that will keep the system powered for 35 - 40 minutes (Abiomed).

\subsection{Patient-Carried Electronics:}

The patient using the AbioCor System is not forced to stay in bed hooked up to the systems

Console; he is also given the option to move around and not have to depend on a power outlet to power the system's components. If the patient chooses to be mobile he may use the Patient Carried Electronics (PCE) by plugging the external TET into the PCE's control module. The PCE serves as a portable power supply, and is placed in a shoulder bag called the PCE Battery Bag. The battery bag stores a control module (this module takes the place of

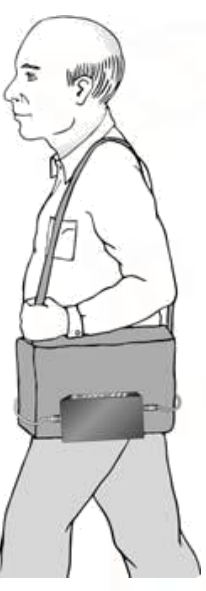
the console when the patient is mobile) and two pairs of batteries.

\subsection{PCE Battery Bag}

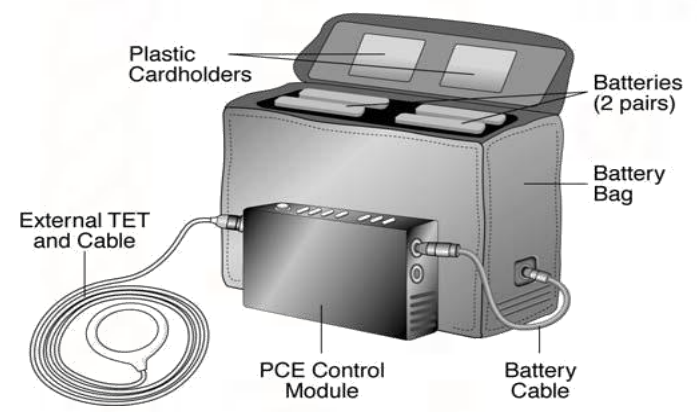

weighs about 10 pounds and may be carried by using an attached shoulder strap (Abiomed). The inside of the bag contains a battery compartment that holds four batteries, and plastic cardholders. The outside of the bag contains pockets used to carry the PCE control module and any extra objects the patient may want to place in them.

\subsection{PCE Batteries:}

Each pair of PCE Batteries supplies the AbioCor's internal system with power for about one hour (Abiomed). Since the battery bag can carry two pairs of PCE batteries, the internal

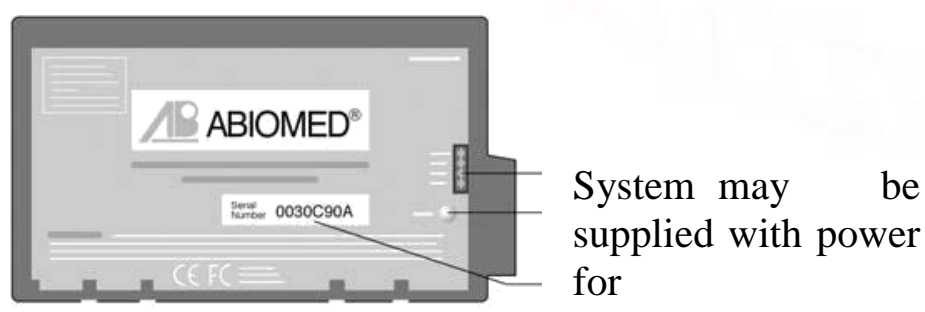

About two hours if the patient uses only the two pairs stored in the battery bag. The batteries used for the 
PCE package differ from common store-bought batteries, the PCE batteries are especially made to power the AbioCor system. Additionally, since the PCE batteries don't last very long, they must be changed several times a day and the patient must be aware of the amount of batteries he will be needing so he can take extra batteries (aside from those located in the battery bag) if necessary.

\subsection{PCE Control Module:}

The PCE control module is to be placed in one of the pockets, located on the outer part of the PCE battery bag, where it is connected to the batteries by

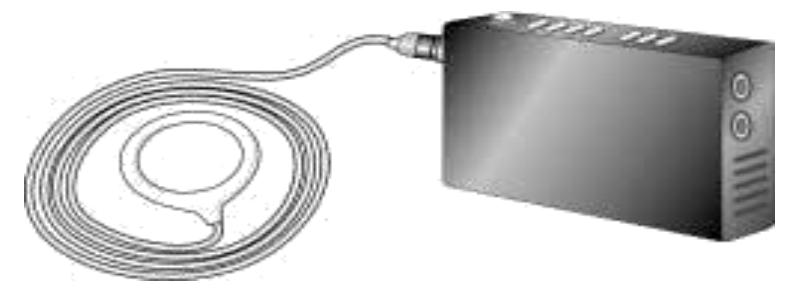

a battery cable and is also connected to the external TET. Instead of being connected to the batteries, the control module may also be connected to any source of Alternating Current (AC) Power by using an AC Power Adapter. Once connected to a power source (batteries or AC Power), the control module converts the energy from the power source into electromagnetic energy in the form of radio waves. By converting the energy from the power source, the external TET is able to transfer energy to the internal TET. The control module, like the console, also monitors the status of all of the AbioCor System's internal components by communicating with the implanted controller through wireless technology. If a problem occurs within one of the internal devices, the control module immediately notifies the patient.

\section{Function}

To maintain operation, the AbioCor System must first have a source of power; depending on whether or not the patient is mobile, this power source will either be the console or the PCE control module. Both power sources cause the AbioCor System to perform the same function and to do so in a similar way. The only difference between the two sources is that the console receives its energy from a power outlet and is stationed in one place and the PCE control module receives its energy from a battery pack carried in the PCE battery bag and is portable. From the power source, energy will travel through the external TET in the form of radio waves. These radio waves will penetrate the patient's skin and enter the implanted TET, which will then convert the radio waves into electrical energy. This electrical energy will travel to the implanted battery where it will remain to keep the battery charged. The energy stored in the battery will be used by the implanted controller to monitor the thoracic unit's (artificial heart) cardiac output rate. This energy supplied to the artificial heart keeps the blood flowing into the heart and out into the body. The heart will take turns in sending blood to the lungs and to the rest of the body because it cannot

\section{CONCLUSION}

The AbioCor System consists of a set of internal components and external components. The internal components are those located inside the patient's body; they are the thoracic unit (artificial heart), the internal Transcutaneous Energy Transmission (TET), the implanted controller, and the implanted battery. The external components are those located outside of the patient's body; these are the external Transcutaneous Energy Transmission (TET), the console, the Patient-Carried Electronics (PCE), the PCE battery bag, the PCE batteries, and the PCE components keep the artificial heart control module. The PCE control module pumping blood and keep sending that blood and the console both serve to provide the throughout the patient's body. Whole system with energy. The internal and external TETs work together to convert this energy into usable energy for all internal components and to transport that energy from the patient's exterior to the patient's interior. Once the energy has reached the patient's interior, it is used to maintain the implanted battery charged and to provide power for the artificial heart and for the implanted controller. All of these components keep the artificial heart pumping blood and keep sending that blood throughout the patient's body.

\section{REFERENCES}

1) Bonsor, Kevin. How Artificial HeartsWork.<http://science.howstuffworks .com/artificial-heart.htm>

2) Leung, Benedict, Dean Zhao. Physiological Fluid Mechanics Artificial Heart. $<$ http://www.ece.mcmaster.ca/ ibruce/courses/EE 3BA3_presentation5.pdf>

3) Rogers, Stuart E., Paul Kutler, and Cetin Kiris. "Numerical Stimulation of Flow Through an Artificial Heart". National Aeronautics and 
Space Administration (NASA). April 1989: 102183

4) Leung, Benedict, Dean Zhao. Physiological Fluid Mechanics Artificial Heart.

5) <http://www.ece.mcmaster.ca/ ibruce/courses/EE 3BA3_presentation5.pdf>

6) https://en.wikipedia.org/wiki/Artificial_heart

7) https://www.ncbi.nlm.nih.gov/books/NBK234425/

8) https://www.nap.edu/read/1820/chapter/4

9) ieeexplore.ieee.org/iel5/10/2331/00064461.pdf

10) https://books.google.co.in/books?isbn=443165964
11) IEEE Transactions on Biomedical Engineering

12) http://ieeexplore.ieee.org/document/64461/

13) https://en.wikipedia.org/wiki/Artificial_heart

14) https://www.thoughtco.com / Inventions , Important Inventions

15) healthcare.utah.edu > U of U HealthFeed Blog > Blog Postings > $2012>$ December

16) https://www.heartfoundation.org.au/images/.../Arti fical-hearts-information-sheet.pdf 